\title{
Acute Type B Dissection Complicated by Aortic Coarctation
}

\author{
Ashish Bahadur Singh, Zhe Yang, Tianqi Zhang, Jianhua Liu, Bikash Ale, Xueli Han* \\ Department of Radiology, The Second Hospital of Jilin University, Changchun, China \\ Email: *hanxueli6613@sina.cn
}

How to cite this paper: Singh, A.B., Yang, Z., Zhang, T.Q., Liu, J.H., Ale, B. and Han, X.L. (2017) Acute Type B Dissection Complicated by Aortic Coarctation. Advances in Computed Tomography, 6, 1-5. https://doi.org/10.4236/act.2017.61001

Received: January 8, 2017

Accepted: February 6, 2017

Published: February 9, 2017

Copyright (c) 2017 by authors and Scientific Research Publishing Inc. This work is licensed under the Creative Commons Attribution International License (CC BY 4.0).

http://creativecommons.org/licenses/by/4.0/

\begin{abstract}
We report a case of acute type B aortic dissection complicated by coarctation of aorta in 35-year-old women. Computed tomography angiography (CTA) showed a short segment aortic narrowing with diameter of $9.2 \mathrm{~mm}$ a small intimal tear, a true lumen, a false lumen, a markedly thick mural thrombus and pleural effusion. Open surgical procedure was performed and the aortic coarctation (CoA) and aortic dissection were resected and a $24-\mathrm{mm}$ prosthetic graft was anastomosed. No pseudo aneurysms were present at the anastomosis sites on the follow up CTA.
\end{abstract}

\section{Keywords}

Aortic Dissection, Coarctation, Anastomosed, Computed Tomography Angiography

\section{Introduction}

Acute type B dissection is a life threatening condition that is associated with a very high mortality rate [1]. The correct diagnosis of the acute type $B$ dissection can be a challenging job because aortic dissection has "many faces". It can mimic other disease conditions such as heart attack, stroke, acute abdomen or the patient may present with ischemic limb. Here in our case of study the patient came with the classical presentation of acute type B aortic dissection, intense and severe inter scapular pain, often described by the patients as the worst pain they have ever experienced. Even though the patients project different symptoms, compromised arterial inflow to some branch of the aorta due to aortic dissection can justify the condition [2].

\section{Case Study}

A 35-year-old woman admitted to our hospital with sudden intense cough and 
severe inter scapular pain described as tearing character by the patient, nausea and vomiting were also observed. Physical examination revealed a blood pressure of 180/90 mm Hg. The past medical history included hypertension without effective treatment. The biochemical and hematological results revealed mild leukocytosis. Computed tomography angiography (CTA) showed a short segment aortic narrowing with diameter of $9.2 \mathrm{~mm}$ (Panel A and C, curved white arrow), a small intimal tear (Panel B, black arrow), a true lumen (Panel A-F, black star), a false lumen (Panel A, B and F, white star), a markedly thick mural thrombus (Panel A, B and E, white arrow), and pleural effusion (Panel A and B, white arrowhead) (Figure 1).

The patient underwent open surgical repair, the aortic coarctation (CoA) and aortic dissection were resected and a $24-\mathrm{mm}$ prosthetic graft was anastomosed. Pathology was suggestive of inflammatory cell infiltrate (Panel D). The postoperative course was uneventful, and she was discharged on postoperative day 31. The follow-up CTA revealed no pseudo aneurysms at the anastomosis sites.

\section{Discussion}

The narrowing of aortic arch distal to the left subclavian artery is termed as coarctation of aorta [3]. It is not only limited to the narrowing of aorta but occurs as an isolated stenosis or as a long, hypoplastic aortic segment so can be considered as a complex disease of the vasculature. The common site of occurrence of CoA is typically at ductus arteriosus insertion point. In rare cases it may occur ectopically at ascending, descending or abdominal aorta. Aortic coarctation and Acute type B aortic dissection are very rarely combined [4]. Fatal or severe morbidity can occur when left CoA untreated. Acute dissection mainly Stanford type A can complicate $\mathrm{CoA}$ in occasional cases. Much rare finding is Acute Stanford type B dissection whose treatment of choice is a high risk surgery
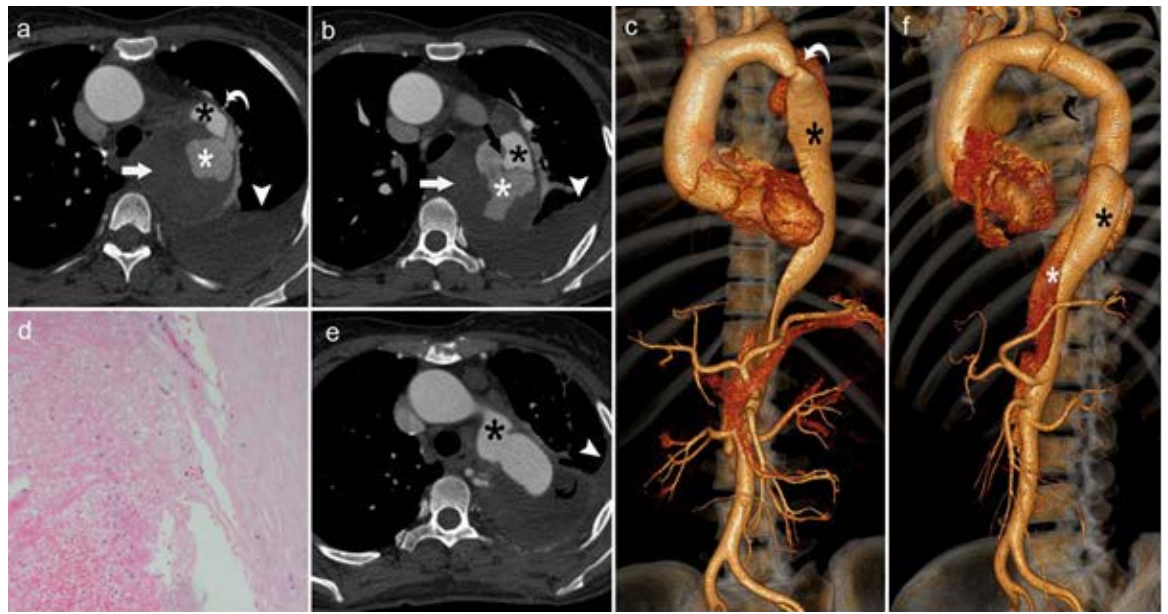

Figure 1. Computed tomography angiography (CTA) showed a short segment aortic narrowing with diameter of $9.2 \mathrm{~mm}$ (a and c, curved white arrow), a small intimal tear (b, black arrow), a true lumen (a-f, black star), a false lumen ( $a, b$ and $f$, white star), a markedly thick mural thrombus ( $a, b$ and e, white arrow), and pleural effusion ( $a$ and $b$, white arrowhead). 
[3]. It accounts for $5 \%$ to $8 \%$ of all congenital heart diseases and prevalence of 3 per 10,000 live births [5]. CoA is commonly detected during childhood life or, in the case of reoccurrence, it may be diagnosed later. There are two classifications for Acute type B dissection, uncomplicated and complicated. Conservative management is considered the standard option for acute uncomplicated type B dissection. If the patient develops dissection related complications surgical repair and endovascular intervention are carried out. Here $25 \%$ of the cases may have complicated dissection [6]. In the uncomplicated aortic dissection there is a presence of rupture or impending rupture, malperfusion and or refractory pain or hypertension. Most recently Thoracic Endovascular Repair (TEVAR) has been the first choice of treatment for complicated dissection which accounts for 10 to $15 \%$ cases of Acute type B dissection [7].

Surgical treatment of COA started in 1945, and till today remains treatment of choice. Recently more non-invasive treatment modalities have been discovered such as balloon dilation or stent implants [8]. The treatment modality of acute type B aortic dissection can be conservative, surgical, endosurgical or a combination of these methods. Conservative management includes Antihypertensive therapy, pain management. Aortic graft replacement, surgical flap fenestration, extraanatomic bypass are some of the examples of surgical management. In the case of endosurgical treatment interventional flap fenestration, true lumen stenting, catheter based reperfusion, stent graft implantation are some of the examples.

As all the treatment procedures have their own indications, contraindications, benefits and risk factors, the above mentioned techniques also has their pros and cons. Minimally invasive surgeries are gaining increased popularity in the last decade due to their simplicity and low risk factors. Endovascular therapy has replaced conventional surgery at present. Surgery may not be the first choice in cases of complicated Type B aortic dissection [5]. Despite new emerging techniques, open surgery is still carried out. The reasons behind may be lack of endosurgical equipment in all centers, lack of skilled people or the fact that endosurgery may not necessarily be more cost-effective than surgical reconstruction [1]. The perioperative mortality rate in open surgery ranges from $5 \%$ to $10 \%$. This rate could exceed up to $70 \%$ in some complicated cases. In the open repair independent prognostic factor for perioperative mortality includes presence of cardiac tamponade, intima tear (location), renal or visceral ischemia, duration of surgery, renal diseases and the presence pulmonary pathology. The assessment between endovascular repair with open repair treatments in complicated type $B$ dissection remains limited due to lack of randomized controlled trials [9].

Clinical presentation has a strong impact on the morbidity and mortality of acute type B aortic dissection. Medical therapy is ideal therapy in all uncomplicated type B dissections, in contrast to the patients with ascending involvement. Medical treatment is desired because current randomized controlled trials have failed to exhibit a favorable outcome of prophylactic endovascular repair in the short term. Patients with complicated dissection are intended to surgical or en- 
dovascular tactics. Nevertheless, surgical procedures have high mortality rates between $20 \%$ to $30 \%$ and in the case of endovascular repair $10 \%$ to $20 \%$ (in acute setting) especially in elderly patients. The progress and outcome of the individual patient in emergency department with acute type B aortic dissection remains unpredictable because of the various clinical features of acute type $B$ aortic dissection [10].

\section{Conclusions}

Coarctation of aorta is rare in adults, and it could occasionally be complicated by Stanford type A. Acute Stanford type B dissection complicated by CoA is a rather rarer finding, especially if it arises spontaneously. The causes of acute type $B$ dissection complicated by aortic coarctation usually arise after angioplasty, or during post surgical treatment. Signs and symptoms are similar to those of aortic dissection, and the CTA plays a critical role in the diagnosis of these diseases.

The impeccable remedy for complicated type B aortic dissection does not exist. When endovascular interventional procedures are not available, they have failed or they are contraindicated, open aortic surgery can be the treatment of choice. There are different ways to manage complicated type B aortic dissection surgically. Surgical fenestration is favored over direct aortic graft replacement, in the absence of rupture or impending rupture. This is the most commonly performed open surgery in the patients with complicated acute type B aortic dissection.

\section{Disclosure}

The authors report no conflicts of interest in this work.

\section{References}

[1] Szeberin, Z., et al. (2015) Early and Long-Term Outcome after Open Surgical Suprarenal Aortic Fenestration in Patients with Complicated Acute Type B Aortic Dissection. European Journal of Vascular and Endovascular Surgery, 50, 1-7.

[2] Ziganshin, B.A., Dumfarth, J. and Elefteriades, J.A. (2014) Natural History of Type B aortic Dissection: Ten Tips. Annals of Cardiothoracic Surgery, 3, 247-254.

[3] Kassaian, S.E., Abbasi, K., Mousavi, M. and Sahebjam, M. (2013) Endovascular Treatment of Acute Type B Dissection Complicating Aortic Coarctation. Texas Heart Institute Journal, 40, 176-181.

[4] Bezgin, T., et al. (2013) Acute Aortic Dissection with a Dangerous Duo in an Adolescent Boy. Cardiovascular Journal of Africa, 24, e10-e12.

[5] Erbel, R., et al. (2014) 2014 ESC Guidelines on the Diagnosis and Treatment of Aortic Diseases. European Heart Journal, 35, 2873-2926.

[6] Singh, M., et al. (2015) Choosing the Correct Treatment for Acute Aortic Type B Dissection. The Journal of Cardiovascular Surgery (Torino), 56, 217-229.

[7] Hughes, G.C., Andersen, N.D. and McCann, R.L. (2013) Management of Acute Type B Aortic Dissection. The Journal of Thoracic and Cardiovascular Surgery, 145, S202-S207. https://doi.org/10.1016/j.jtcvs.2012.11.078

[8] Ang, H.L., Lim, T.C.W., Hia, C.P.P., Yip, J. and Quek, S.C. (2014) Coarctation of 
the Aorta: Nonsurgical Treatment Using Stent Implantation. Singapore Medical Journal, 55, 302-304. https://doi.org/10.11622/smedj.2014080

[9] Geropapas, G., et al. (2015) Acute Type B Aortic Dissection: Update on Proper Management. Journal of Acute Disease, 3, 258-264. https://doi.org/10.1016/S2221-6189(14)60058-5

[10] Tolenaar, J.L., et al. (2014) Predicting in-Hospital Mortality in Acute Type B Aortic Dissection Evidence from International Registry of Acute Aortic Dissection. Circulation, 130, S45-S50. https://doi.org/10.1161/CIRCULATIONAHA.113.007117

Submit or recommend next manuscript to SCIRP and we will provide best service for you:

Accepting pre-submission inquiries through Email, Facebook, LinkedIn, Twitter, etc. A wide selection of journals (inclusive of 9 subjects, more than 200 journals)

Providing 24-hour high-quality service

User-friendly online submission system

Fair and swift peer-review system

Efficient typesetting and proofreading procedure

Display of the result of downloads and visits, as well as the number of cited articles Maximum dissemination of your research work

Submit your manuscript at: http://papersubmission.scirp.org/

Or contact act@scirp.org 